JKEP

Vol 6, No 1 (2021)

ISSN: 2354-6042 (Print)

ISSN : 2354-6050 (Online)

\title{
Aplikasi Asuransi Kesehatan Pada Mahasiswa Keperawatan
}

\author{
Zia Ul Haq, Lailatul Kodriyah, Ida Herwati, Ronal Surya Aditya \\ Sekolah Tinggi Ilmu Kesehatan Kepanjen \\ Email :stkskpnjn@gmail.com
}

\author{
Artikel history \\ Dikirim, Dec $12^{\text {th }}, 2019$ \\ Ditinjau, April 15 ${ }^{\text {th }}, 2021$ \\ Diterima, Mei $6^{\text {th }}, 2021$
}

\section{ABSTRACT}

Health insurance from the government, known as Askes, was renamed BPJS. One of the residents of Indonesia are students who take part in the program. The purpose of this study was to determine the experience of students becoming users of health insurance. Method This research is a qualitative research with a descriptive phenomenological design, data obtained through in-depth interviews. Stages of analysis Data obtained by in-depth interviews can be analyzed the process of data analysis with Interpretative Phenomenological Analysis (IPA). The study population was 15 nursing student respondents. The results showed that there were 8 themes: 1) Health Insurance Services 2) Welfare 3) Hospital Costs 4) Social Health Insurance 5) Economic Problems 6) Time 7) Increase 8) Pain. The conclusion of this study is that students consider that current health services were not good, for example long waiting times and health insurance have an influence on welfare and the economy.

Keyword : application; student; nursing; insurance; social security administrator

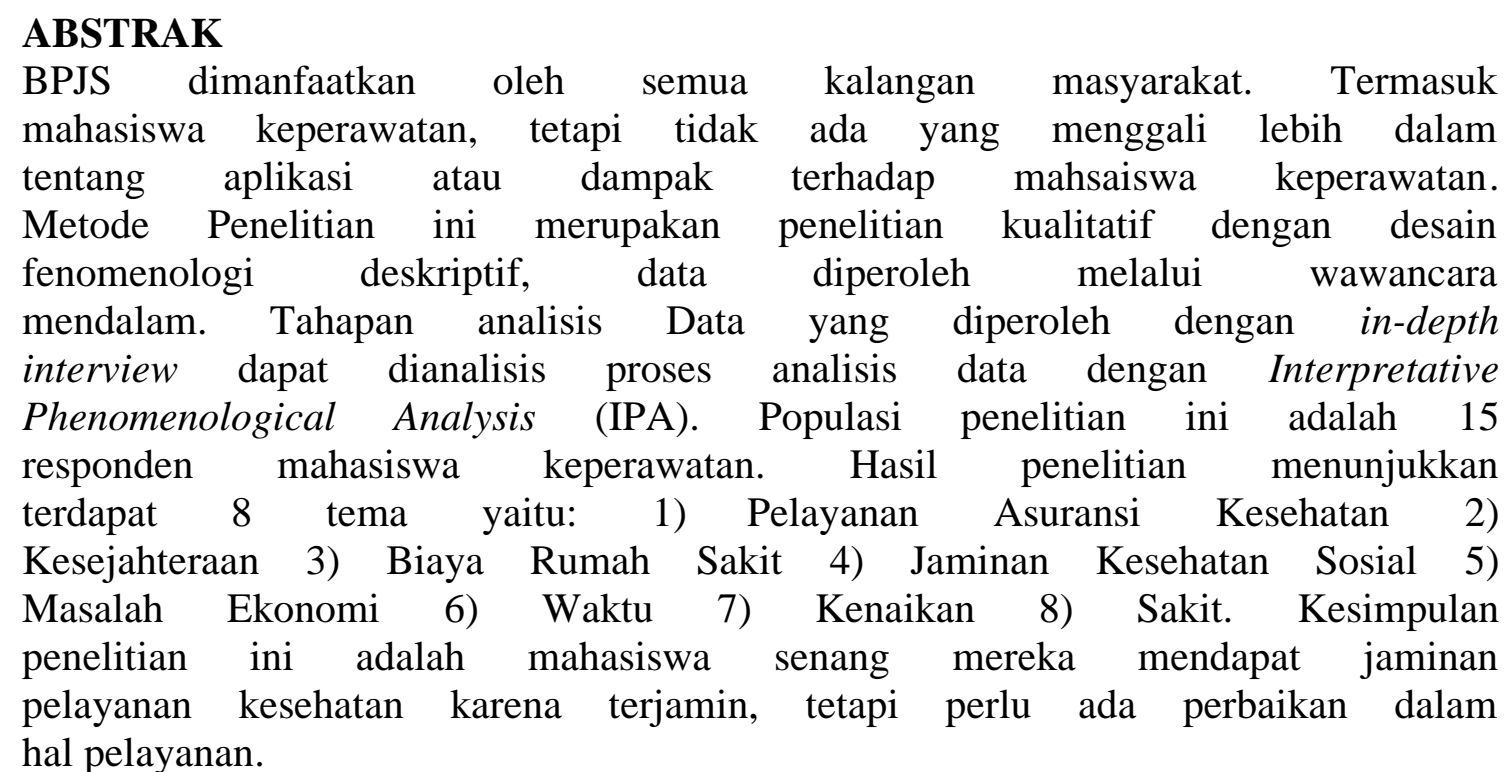

Kata Kunci : Aplikasi, Mahasiswa, Keperawatan, Asuransi, BPJS 


\section{PENDAHULUAN}

Asuransi kesehatan dari pemerintah yang dikenal dengan Askes berganti nama menjadi Badan Penyelenggara Jaminan Sosial (BPJS) Kesehatan (Kusumaningrum and Soewondo, 2018). BPJS ini dibentuk untuk menyelenggarakan program jaminan kesehatan dan semua penduduk Indonesia wajib menjadi anggota BPJS Kesehatan (Rokhaidah; Herlina, 2018). Penduduk Indonesia salah satunya adalah mahasiswa yang ikut dalam program tersebut. Mahasiswa memiliki peran sebagai kontrol sosial, dimana dalam hal ini BPJS yang merupakan salah satu program pemerintah harus bisa memperbaiki masalah kesehatan yang ada di Indonesia. Kontrol sosial dari mahasiswa ini dapat digunakan evaluasi kepada pemerintah dalam perbaikan pelayanan BPJS Kesehatan (Intarti dkk, 2018).

Mahasiswa adalah sebutan bagi orang yang sedang menempuh pendidikan tinggi di sebuah perguruan tinggi yang terdiri atas sekolah tinggi, akademi, dan yang paling umum adalah universitas (Lusiana, Frinaldi and Putri, 2019). Di perguruan tinggi, mahasiswa memiliki keahlian untuk belajar, sehingga termasuk dalam golongan intelegensi, mempunyai kemampuan yang ada, bertindak sebagai pemimpin yang mampu serta terampil, baik sebagai pemimpin masyarakat maupun dalam dunia kerja nantinnya (Aditya, 2017). Kemampuan intelektual, kepekaan sosial serta sikap kritisnya wajib dimiliki mahasiswa dengan pendidikannya (Ika Widiastuti, 2017). Mahasiswa mampu menjadi pengontrol sebuah kehidupan sosial dalam masyarakat dengan cara memberikan saran, kritik dan juga solusi untuk permasalahan sosial masyarakat maupun permasalahan bangsa.

Dengan tujuan menjamin peserta memperoleh manfaat memelihara kesehatan dan perlindungan dalam memnuhi kebutuhan dasar kesehatan, jaminan kesehatan menurut UU SJSN dilaksanakan secara nasional berdasarkan prinsip asuransi sosial dan prinsip ekuitas. Berdasarkan literatur dan kajian lapangan bahwa belum adanya penelitian yang menggali lebih dalam tentang aplikasi asuransi BPJS Kesehatan kepada mahasiswa keperawatan. Sehingga peneliti tertarik untuk membahas terkait ini. Penelitian ini akan menjadi evaluasi serta masukan kepada pihak terkait. 


\section{METODE}

Penelitian ini dilakukan secara deskriptif Penelitian kualitatif menggunakan pendekatan fenomenologis. Dengan menggunakan metode ini, peneliti ingin mengeksplorasi atau mengungkapkan makna suatu konsep atau fenomena pengalaman berdasarkan kesadaran yang terjadi pada beberapa individu. Penelitian ini dilakukan pada 19 hingga 26 November 2019. Metode pemilihan peserta dilakukan menggunakan probabilitas, dasar pengambilan sampel dengan teknik purposive sampling, yang dianggap cocok sesuai kriteria. Sebanyak 15 peserta yang diwawancarai di penelitian ini adalah remaja berusia 18-20 tahun (diberi kode sebagai P1, P2, P3, P4, P5, P6, P7, P8, P9, P10, P11, P12, P13,P14, P15).

Semua peserta adalah mahasiswa STIKes Kepanjen, Semua peserta menyatakan keinginan mereka untuk memberikan informasi yang dibutuhkan oleh peneliti untuk mencapai tujuan dari penelitian ini. Pengumpulan data dilakukan dengan wawancara mendalam menggunakan suara perekam dan teknik observasi langsung. Wawancara dilakukan secara struktural menggunakan pedoman wawancara disusun oleh peneliti berdasarkan teori respon dan teori phycology. Semua data diperoleh dari wawancara mendalam kemudian dianalisis menggunakan Interpretatif Analisis Fenomenologis (IPA) (Aditya et al., 2017).

\section{HASIL}

Data yang telah didapatkan ini adalah data dari responden yang homogen dengan kriteria usia 19 sampai 26 tahun, pendidikan S1 Keperawatan semester 5. Tema 1: Pelayanan Asuransi Kesehatan Mahasiswa mempunyai pandangan dalam pelayanan Asuransi Kesehatan. Dalam Pelayanan Asuransi Kesehatan ini memiliki 2 tema yaitu dengan pelayanan sekarang, dulu dengan pelayanan yang kurang baik dibuktikan pada responden yakni:"jelek banget pelayanan asuransi kesehatan ini dari dulu sampai sekarang”, p1,p5,p6,p7 serta harapan kedepannya yang agar pelayanan tersebut lebih baik sesuai dengan hasil wawancara "Asuransi Kesehatan ini kenapa kok gak diperbaiki, ayo diperbaiki mulai sekarang agar lebih baik kedepannya" pada responden” $\mathrm{p} 2, \mathrm{p} 4, \mathrm{p} 6$

Tema 2: Kesejahteraan 
Kesejahteraan adalah hal utama yang menjadi tujuan dalam asuransi kesehatan tersebut salah satunya meringankan beban beban ekonomi terkait masalah kesehatan berkurang, baik dahulu, sekarang dan kedepannya. Hal tersebut terbukti pada respoden p1,p2,p3,p4,p5,p6,p7,p8,p15 “Kami merasa sangat terbantu, dengan adanya bpjs ini sangat membantu kami saat keluarga saya sakit, biaya gratis"

Tema 3: Biaya Rumah Sakit

Biaya Rumah Sakit yang tinggi membuat rakyat Indonesia menjadi kesulitan dalam menggunakan layanan kesehatan. Asuransi Kesehatan ini membantu mengurangi beban. Hal ini dibuktikan pada responden p3,p4,p5,p6,p8,p14, dengan pernyataan berikut: "kami rakyat indonesia tidak semuanya mempunyai uang banyak, kesehatan mahal, Pengobatan itu mahal tapi dengan adanya ini terbantu."

Tema 4: Jaminan Kesehatan Sosial Jaminan Kesehatan Sosial yang ada di indonesia salah satunya yaitu jaminan dalam bidang layanan kesehatan, terbukti pada responden p11,p3,p4 "Asurasni Kesehatan ini adalah salah satu jaminan social, yang dapat mensejahterakan kami rakyat Indonesia"

Tema 5: Masalah Ekonomi

Masalah Ekonomi menjadi salah satu faktor dalam penggunaan layanan kesehatan yang di Indonesia, dibuktikan pada responden p2,p3,p4,p5,p6,p8,p13 "kami tidak punya uang untuk beorbat, kami terkendala dalam masalah biaya"

Tema 6: Waktu

Waktu merupakan salah satu indikator utama dalam pelayanan asuransi kesehatan. Waktu tunggu menjadi penentu utama masyarakat menggunakan asuransi kesehatan yang dapat digunakan dalam layanan kesehatan. Pelayanan asuransi Kesehatan yang sebelum adanya system online membutuhkan waktu tunggu yang lama sehingga masyarakat kurang responsive terhadap penggunaan, tetapi dengan adanya sistem online, maka system pelayanan menjadi lebih efektif dan efisien dibuktikan pada responden p1,p2,p5,p12 “waktu nya itu loh lama kalau makai kartu ini tapi siapa tau bisa diperbaiki kedepannya, kenapa selalu lama kalau pakek kartu asuransi kesehatan ini, tetapi saat menggunakan 
system online semuanya terasa lebih cepat"

\section{Tema 7: Kenaikan}

Kenaikkan tarif asuransi kesehatan ini menjadikan banyak harapan bagi pengguna asuransi kesehatan ini untuk perbaikan dalam segi kualitas pelayanan dibuktikan pada responden p3,p4,p6,p7,p8,p9,p11 “kenapa harus naik, kenapa pemerintah tidak memikirkan rakyat nya kalau harus naik, asuransi kesehatan naik mungkin untuk memperbaiki kualitas nya"

Tema 8: Sakit

Sakit adalah suatu keadaan yang tidak diharapkan oleh suatu individu, dalam keadaan tersebut seorang individu akan melakukan berbagai upaya untuk bisa keluar dalam keadaan tersebut. Individu yang telah memiliki asuransi kesehatan akan lebih mudah menemukan solusi dalam keadaan tersebut terbukti pada responden p2,p3,p4,p5,p10 “Adik saya jatuh kecelakaan sakit dan saya pakai BPJS itu”

\section{PEMBAHASAN}

Hasil penelitian tema yang pertama yaitu layanan kesehatan. Di dalam layanan kesehatan terdapat sub tema layanan kesehatan dahulu, sekarang serta harapan kedepannya (Aditya, 2019a) dalam layanan kesehatan tersebut. Hal ini sejalan dengan komitmen BPJS terkait dengan layanan dalam bentuk pelayanan kesehatan yang bersifat menyeluruh (komprehensif) berdasarkan kebutuhan medik (Yusuf et al., 2017). Pelayanan yang baik maka mempengaruhi Kesejahteraan Pelanggan. Hal ini sejalan dengan sub tema yang kedua meringankan beban dibentuknya asuransi layanan kesehatan ini di Indonesia (Kementerian Kesehatan Republik Indonesia, 2016).

Layanan kesehatan ini seiring dengan biaya rumah sakit dengan sub tema tingginya nominal yang harus dikeluarkan dalam mencapai sehat. Hal ini sejalan dengan penetapan tarif rasional layanan kesehatan di Rumah Sakit (Riskesdas, 2018). Di rumah sakit terdapat jaminan sosial untuk pengguna layanan salah satunya yaitu Jaminan Kesehatan Nasional. Hal ini sejalan dengan Jaminan Kesehatan Nasional (JKN) merupakan bagian dari Sistem Jaminan Sosial Nasional (SJSN) yang diselenggarakan menggunakan mekanisme asuransi kesehatan sosial yang bersifat wajib dimiliki oleh warga 
negara Indonesia (Aditya, Solikhah, dan Kurniawan, 2019).

Jaminan Kesehatan ini untuk mengatasi masalah ekonomi dimana biaya pengobatan individu yang tidak sebanding. Hal ini sejalan dengan biaya pengobatan di rumah sakit yang tinggi sesuai dengan kebijakan standar nasional rumah sakit dan dengan demikian PDB per kapita saat ini adalah sekitar Rp 56 juta/tahun (dari angka $\mathrm{Rp} 15$ triliun dibagi 265 juta penduduk). Rp 56 juta setahun artinya dalam sebulan $=\operatorname{Rp} 4,6$ juta. Rp 4,6 juta/bulan - inilah rata-rata penghasilan orang Indonesia saat ini. Berdasarkan data pendapatan tersebut masih banyak warga Indonesia yang pendapatan di bawah rata-rata (Ika Widiastuti, 2017).

Pendapatan yang tidak sebanding dengan biaya pengobatan membuat banyak individu yang memakai jaminan kesehatan ini untuk meringankan beban (Aditya et al., 2020). Dalam penggunaannya proses waktu tunggu masih lama. Hal ini sejalan dengan hasil survei BPJS Watch Jatim yang menemukan permasalahan, yakni lamban dan lamanya waktu tunggu yang dibutuhkan untuk mendapatkan pelayanan kesehatan (Wayan Suardana, Yusuf and Purnomo, 2018).

Asuransi Kesehatan dalam hal ini BPJS telah mempunyai rancangan per januari 2020 biaya iuran BPJS akan mengalami kenaikan $100 \%$. Hal ini sejalan dengan munculnya beberapa pandangan masyarakat terkait dengan harapan kualitas pelayanan yang akan menjadi lebih baik (Kozier, 2008). Layanan Asuransi Kesehatan yang mengalami kenaikan $100 \%$ ini untuk membantu penderita atau keluarga pengguna BPJS jika mengalami keadaan sakit yang membutuhkan biaya pengobatan yang lebih. Hal ini sejalan dengan sasaran BPJS adalah seluruh pengguna asuransi BPJS memenuhi kebutuhan dasar kesehatannya (Aditya, Qur'aniati and Krisnana, 2014).

\section{KESIMPULAN}

Mahasiswa memiliki pendapat terkait dengan sistem jaminan kesehatan. Mahasiswa menganggap bahwa pelayanan kesehatan sekarang, dulu kurang baik seperti contoh waktu tunggu yang lama dan Jaminan Kesehatan tersebut memiliki pengaruh pada kesejahteraan dan ekonomi pelanggannya. Biaya rumah sakit yang 
tinggi sedikit berkurang dengan adanya jaminan kesehatan ini. Jaminan sosial didukung pula dalam layanan ini seperti orang dalam keadaan sakit. Kenaikan jaminan asuransi kesehatan ini harus diimbangi dengan sistem pelayanan.

\section{DAFTAR PUSTAKA}

Aditya, R. S. et al. (2017) 'Experience of the Healthworkers in Conductin Methadone Rehabilitation Therapy at the Public Health Center', Dama International Journal Researchers (DIJR), 2(2), pp. 107-113.

Aditya, R. S. (2017) 'Phenomenology Study of the Experience of Relapse of Drug Addictions During Methadone Therapy', Perpustakaan Universitas Airlangga.

Aditya, R. S. (2019a) Perbandingan Metode Health Coaching dan Ceramah Tentang Basic Life Support (BLS) Untuk Remaja Masjid, Jurnal Keperawatan BSI. Available at: http://ejurnal.univbsi.id/index.php/ke perawatan/article/view/105

(Accessed: 1 November 2019).

Aditya, R. S. (2019b) 'Teenager Response to the Conditions of Basic Level Emergency: A Phenomenology Study', Indian Journal of Public Health, 10(1), p. 170.

Aditya, R. S., Qur'aniati, N. and Krisnana, I. (2014) 'Influence of Health Education Short Film Media Lecture Methods on Knowledge, Attitudes, and Practices of Mother About Early Detection of Children Diphtheria Cases'.
Ika Widiastuti (2017) 'PELAYANAN BADAN PENYELENGGARA JAMINAN SOSIAL (BPJS) KESEHATAN DI JAWA BARAT', pp. 91-101. Available at: http://www.ghbook.ir/index.php?na me= فرهن نوين\&option=com_dbook\&task=read online \&book_id $=13650 \&$ page $=73 \&$ chkhashk=ED9C9491B4\&Itemid=21 $8 \&$ lang $=$ fa\&tmpl=component.

Intarti dkk, W. D. (2018) 'Faktor-Faktor yang Mempengaruhi Pemanfaatan Posyandu Lansia', Journal of Health Studies, 2(1), pp. 110-122. doi: 10.31101/jhes.439.

Kementerian Kesehatan Republik Indonesia (2016) Peran Keluarga Dukung Kesehatan Jiwa Masyarakat. Available at: https://www.kemkes.go.id/article/pri $\mathrm{nt} / 16100700005 /$ peran-keluargadukung-kesehatan-jiwamasyarakat.html (Accessed: 1 November 2019).

Kozier, B. (2008) Fundamentals of nursing: concepts, process and practice. Pearson Education. Available at: https://books.google.co.id/books/abo ut/Fundamentals_of_Nursing.html?hl =id\&id=_0_pRyy9McQC\&redir_esc =y (Accessed: 13 June 2019).

Kusumaningrum, F. and Soewondo, P. (2018) 'Peran Jaminan Kesehatan Terhadap Pemanfaatan Tenaga Kesehatan Sebagai Penolong Persalinan Di Indonesia (Analisis Data Susenas 2017)', Jurnal Kesehatan Reproduksi, 9(2), pp. 109124. doi: 10.22435/kespro.v9i2.1092.109-124. 
Lusiana, Y., Frinaldi, A. and Putri, N. E. (2019) 'PENGARUH KUALITAS PELAYANAN TERHADAP KEPERCAYAAN PESERTA PBPU BPJS KESEHATAN PADA BPJS KESEHATAN CABANG PADANG DI KOTA PADANG', 2(1), pp. 8696.

Riskesdas (2018) 'Hasil Utama Riskesdas Penyakit Tidak Menular 2018', Hasil Utama Riskesdas Penyakit Tidak Menular, p. 8.

Yusuf, A. et al. (2017) Qualitatif Research in Nursing. 1st edn. Surabaya: Mitra Wacana Media.
Rokhaidah; Herlina (2018) 'Studi Fenomenologi Pengalaman Orangtua dalam Merawat Anak dengan Diagnosis Kanker', Jurnal Kedokteran dan Kesehatan, pp. 3138.

Wayan Suardana, I., Yusuf, A. and Purnomo, W. (2018) 'Self-help group therapy: The enhancement of selfcare ability and quality of life among the elderly in Bali, Indonesia', Indian Journal of Public Health Research and Development, 9(11), pp. 17571761. doi: 10.5958/09765506.2018.01698.4. 